\title{
Comparative Study between Vickers and Knoop Micro-hardness of Ultra High Temperature Ceramics
}

\author{
Naidu Seetala ${ }^{1}$, Ashirah Simpson $^{1}$, Cyerra Prevo $^{1}$, Lawrence Matson $^{2}$, and HeeDong Lee ${ }^{3}$ \\ 1. Department of Mathematics \& Physics, Grambling State University, Grambling, LA, USA. \\ 2. Air Force Research Laboratory, Materials and Manufacturing Directorate, Wright-Patterson Air Force \\ Base, Dayton, OH, USA. \\ 3. UES, Inc., Dayton, OH, USA.
}

Ultra-high temperature ceramics such as $\mathrm{ZrB}_{2}$ and $\mathrm{HfB}_{2}$ with small percentage of SiC are useful as structural materials for applications in leading edge of hypersonic vehicles [1]. Spark plasma sintering (SPS) technique is used for densifying the UHTCs under the influence of uniaxial pressure and pulsed direct current [2]. Fine grain, low porosity, and high densification yield higher micro-hardness ceramics those can be used for high temperature oxidation resistant materials. Here we made a comparative study between Vickers and Knoop micro-hardness of SPS consolidated UHTC composites starting with micron- and nano-powders.

Micron-size $(\sim 1 \mu \mathrm{m})$ or nano-size $(\sim 40-60 \mathrm{~nm})$ powders of $\mathrm{ZrB}_{2}$ or $\mathrm{HfB}_{2}$ and 20 vol\% $\mathrm{SiC}$ of comparable size powders were mixed and sintered at high temperatures $\left(1,800-2,100^{\circ} \mathrm{C}\right)$ while applying high pressures $32 \mathrm{MPa}$ using Spark Plasma Sintering equipment at Wright-Patterson Air Force Base, Dayton, $\mathrm{OH}$. Polished surfaces were studied for micro-hardness using Vickers and Knoop micro indenters at different applied forces (500gf and 1,000gf loads) with dwell time of $20 \mathrm{sec}$. We used a FEI Quantum-2 SEM for granular size determination.

The micro-indentations using Vickers and Knoop indenters with 1,000gf load are compared in Fig. 1 and 2. First, we compare the Vickers hardness results for two applied force loads - 500gf and 1,000gf. The average area of indentation is about $250 \mu \mathrm{m}^{2}$ for $500 \mathrm{gf}$ load (with hardness vs area slope of $\sim 4.7$ $\mathrm{VHN} / \mu \mathrm{m}^{2}$ ), and $\sim 700 \mu \mathrm{m}^{2}$ for the $1000 \mathrm{gf}$ load (with the slope about half of the $500 \mathrm{gf}$ load, see Fig. 3). The SEM observations provided the average grain size ranged from 0.5 to $2 \mu \mathrm{m}$ for composites starting with nano-powders, and from 6.5 to $9.5 \mu \mathrm{m}$ for composites starting with micron-powders. Fig. 4 shows a relation between the micro-hardness and the grain size. As the grain size increases, the hardness decreases. The estimated number of grains under the micro-hardness indenter are $\sim 25$ at $500 \mathrm{gf}$ load and $\sim 100$ at $1,000 \mathrm{gf}$ load for nano-composites, while these numbers are very small 1-4 grains for microcomposites. This indicates that for more accurate representation of the sample hardness, we need to use higher load. Thus, 1,000gf load is selected to compare between Vickers and Knoop hardness measurements. The area of indentation with Knoop indenter is about 1.24 times of the area in Vickers indentation at the same 1,000gf. The average percent errors obtained from the standard deviation of the micro-hardness values show around 13\% in Vickers, while it is around 10.3\% in Knoop hardness values.

Although the area covered by the Knoop is slightly larger, Knoop's micro-hardness values are lower than that of the Vickers for all samples. This may be due to the uneven pressure applied on the grains, because of the narrow shape of Knoop indenter. The uneven pressure on individual grains is evident by the extended damage from Knoop indentations observed in SEM as shown in Fig. 5 (which is not seen in Vickers). For low hardness materials, the uneven pressure on individual grains diminishes as the indentation area is much larger. This is supported by the literature [3] where Knoop's hardness vales are 
higher than Vickers' hardness at low hardness range $(<900 \mathrm{VHN}=8.8 \mathrm{GPa})$ and other way round at higher hardness range. Our data agrees with this trend as summarized in Fig. 6, where all data points for our UHTC composites (above 1,200 Vickers hardness) are below the $45^{\circ}$ dotted line, indicating lower values for Knoop hardness compared to Vickers hardness.

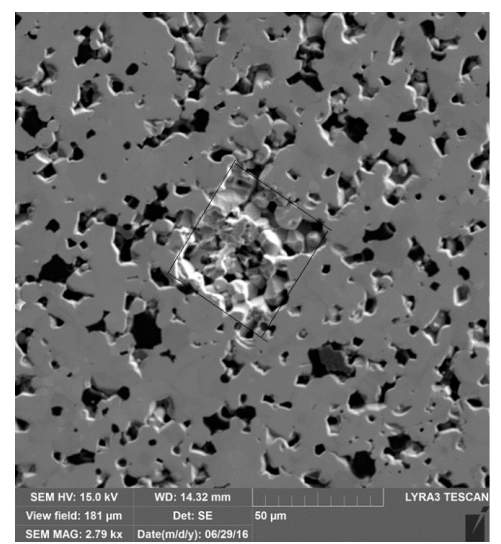

Figure 1. Vickers indentation.

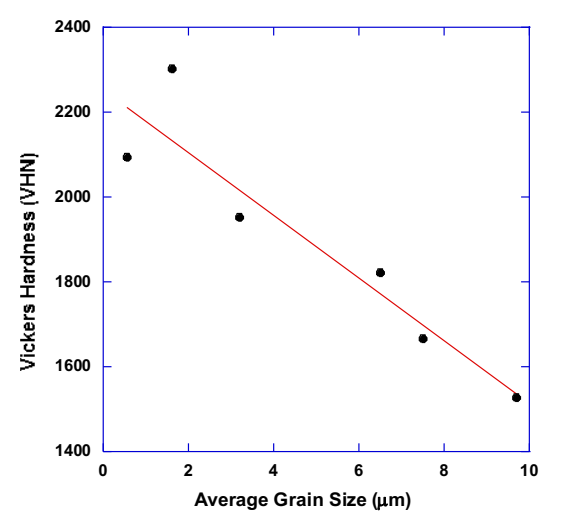

Figure 4. Vickers hardness vs. average grain size

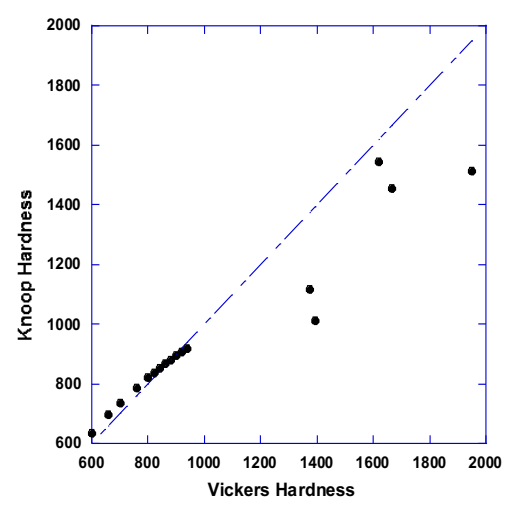

Figure 6. Vickers vs. Knoop micro-hardness comparison.

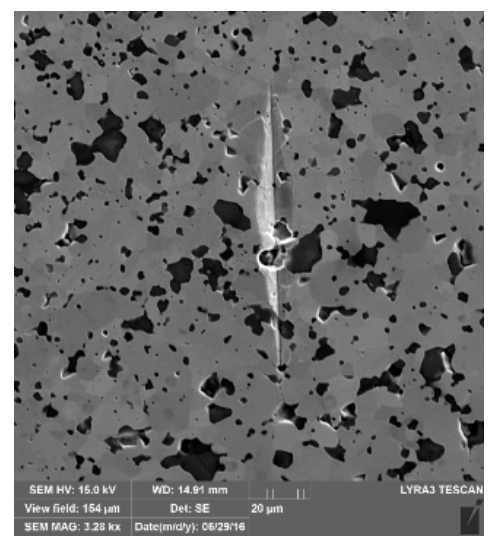

Figure 2. Knoop indentation.

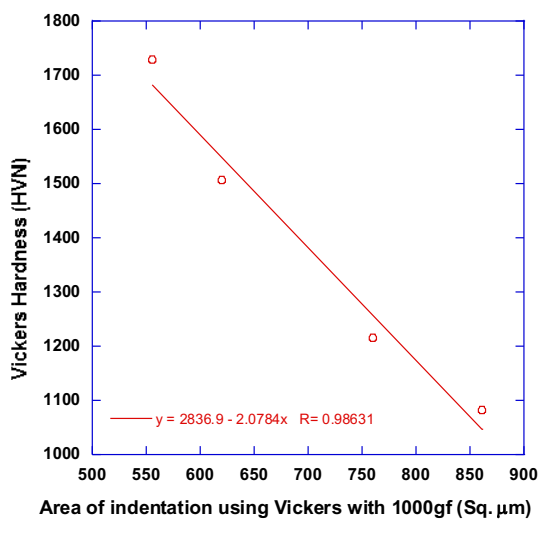

Figure 3. Vickers Hardness vs. area of indentation at $1,000 \mathrm{gf}$.

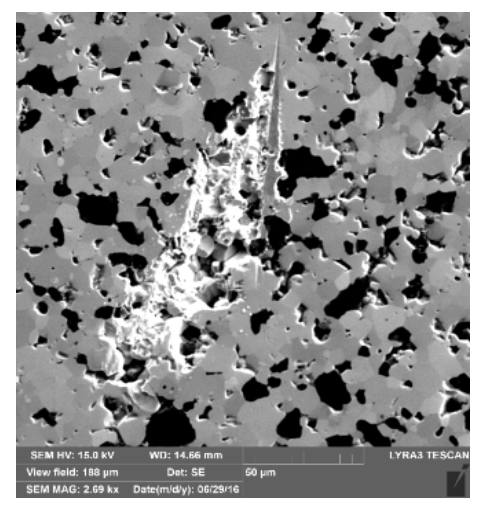

Figure 5. Knoop indentations at 1,000gf force, showing extended damage from the indentation.

This study reveals that for harder materials such as UHTC composites and especially when the grain sizes are comparable to the microindenter dimensions, Vickers hardness test with higher load is better option than Koop hardness [4].

\section{References:}

[1] W. G. Fahrenholtz, et al, J. Am. Ceram. Soc. 90 (2007), p. 1347.

[2] R. K. Enneti, et al, Int. J. Refractory Metals \& Hard Matter. 31 (2012), p. 293.

[3] D. Chicot, et al, J. Euro. Ceram. Soc. 27 (2007), p. 1905.

[4] This work is supported by Air Force Contract FA8650-13-C-5800. 